\title{
Violence Against Women Affects Child's Personality: Perceptions Of The Mothers And Their Adolescent
}

\author{
Madieha Akram \\ \& \\ Zahira Batool \\ Department of Sociology \\ Government College University, Faisalabad
}

\begin{abstract}
Adolescents show distress when their parents have conflicts. Their common reactions are fear, anxiety, anger and sadness. The main objective of the study was to investigate the effects of violence against women at home on the personality development of the adolescents. To get meaningful information both methods of quantitative and qualitative research were used. A cross-sectional research was conducted in all four urban towns of District Faisalabad, Punjab, Pakistan. A random sample of 400 adolescents and their mothers ( 25 from each union council) were taken through pre-designed interviewing schedule. In qualitative study detailed information through 8 focus group discussions of 4-12 mothers of the adolescents were collected. Uni-variate and bi-variate analysis demonstrates the connection among the variables. Results showed that the majority of those mothers who had a high level of violence in their home had high levels of bad effect on their adolescent's personality development.
\end{abstract}

Keywords: Violence on Women, Adolescent, Personality Development, Parents, Conflicts.

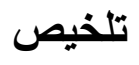

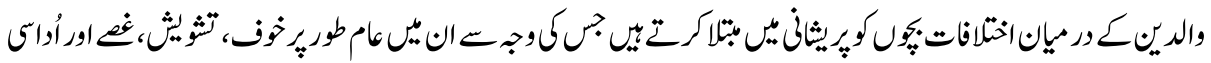

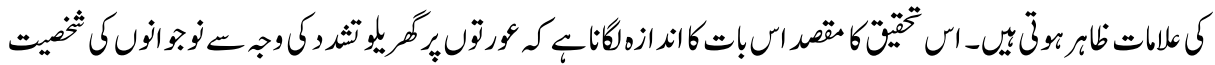

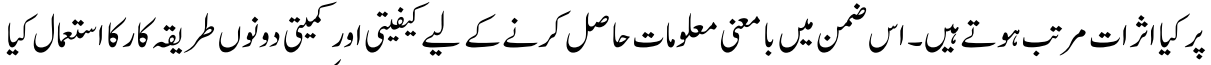

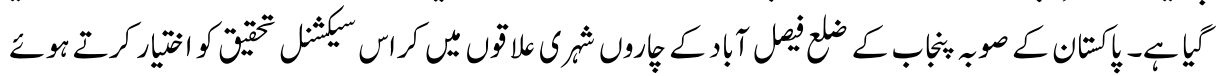

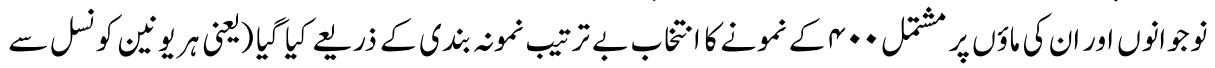

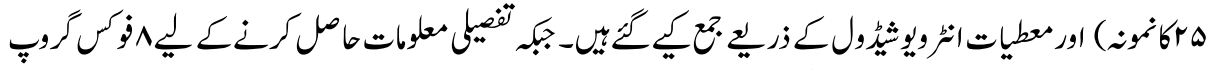

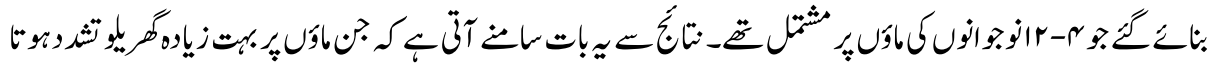

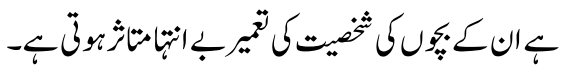

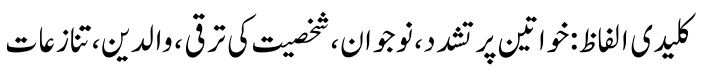




\section{Introduction}

Parents are the gift of God. They perform an immense responsibility of personality development of their children. The total population of Pakistan is 207.3 million. The male population in urban areas is $1,931,770$ while female population is $1,828,23$. The adolescent (10-19 years) population in rural areas is 22.80 percent, while the adolescent population in urban areas is 24.39 percent (Pakistan Bureau of Statistics, 2017).

There are diverse ways of socializing adolescents and of bringing up children. These behaviors, foster positive or negative thoughts, therefore promoting societal development. The personality of the adolescent develops from the interaction of adolescent and parent (Einsenberg et al., 2001). There is sure ecological setting that a mother can give to improve the advancement furthermore the fitness of their adolescents. It's an essential bit of the human child to twist up evidently attached to a mother figure, in light of the way that strong mother-youthful association is an imperative antecedent of the early energy from other people and can be a major precondition for the personality change (Martins and Gaffan, 2000).

The examination of personality focuses on two wide domains: One is understanding individual complexities particular character qualities, for instance, kind disposition or irritability. The other is perceiving how the diverse parts of a man get together all things considered (Encyclopedia of Psychology, 2017). It is the child's representations of the social world and the self as well as the development of social and emotional competence (Thompson et al., 2008). Parents perform a basic role in the socialization of their children. All youngsters experience phases of social improvement. Young people add familiarity of behaviors, values, rules in addition to the actions of their family members.

According to UNICEF, (2000) household violent behavior includes aggression from close associate as well as other family members where it takes place and in what shape it occurs. Regular researches (Hassan et al., 2004; Garcia-Morenoet al., 2006) have announced that this exploitation is practiced everywhere throughout the world, yet its force is higher in South Asian nations (Khosla et al., 2005). Pervez and Iraqi (2018) found that in Pakistan, the violence against ladies happens in numerous structures, for example, honor killings, corrosive assaults, early marriages, human trafficking, rapes, lewd behavior in the working environment and so on. The mental violence that females have to face includes again violence at the domestic and societal level. Violence against mothers effects negatively their children. 
Those parents who use abusive language, violent behavior, their children have chronic effects of personal destruction. Parental conflict influences kids' conduct adversely and inwardly. The social reactions of kids radically influenced by the negative state of mind of guardians (Schermerhorn et al., 2007). The bad temper of family members also affects the personality of the adolescents. A survey shows the feelings of anger 37 percent in adolescents because of the bad temper of the family, 29 percent feel insulted, 1 percent want to run away from home (UNICEF, 2006).

There is a great association between poor role modeling of the parents and children's behavior. Young people will make a move comparable as their parents when they grow to be an adult. A child who continuously hears awful comments regarding father from mother or mother from the father, the hazard is, the parent-child friction may turn down. It can likewise be brought about the invert direction (Eugster, 2007).

\section{Significance of the Study}

Every institution has importance in society, but family is the most important institution with different responsibilities. The primary responsibilities of the family are: goods and services, provision of accommodation, regulation of sex, reproduction, socialization, affection, safeguard of interest, protection, education, religious and cultural values and emotional gratification. The deterioration of personality development starts when the conflict starts between parents. The focus of this study is on the gender based violence against women. Violence badly affects mothers and their adolescents. This research will help to solve or tackle such issues. This social problem needs to be solved on urgent basis because kids are the future of any state.

\section{Objectives of the Research Study}

1. To study the socio-cultural and demographic characteristics of the respondents

2. To assess respondent's attitude towards extent and determinants of parental conflict

3. To find out the effect of violence on adolescent personality

\section{Review of Literature}

Violence is more incessant inside societies where sexual orientation based roles are extremely characterized and connected; where manliness is straightforwardly connected with sturdiness, predominance or male respect. Ezeah, (2013) showed that 56 percent women had experienced domestic violence. Close associate violent behavior is the mainly common form of gender-based aggression universal (Heise et al., 2002). Inside a male overwhelming society, men keep up an advantaged put through their capacity of 
ladies alongside their control of social organizations. Ladies similarly impeding in a network association that guarantees and keep up their subordination by men and predominately male institutions (Renzetti, 1994).

Exposure to hostility on numerous levels can have an effect on the parents' actions, can amalgam the sound effects on the offspring (Osofsky, 1999). Various researches show that in 60 percent to 75 percent of families in which a female is exhausted, preadulthood is additionally worn out (Fantuzzo et al., 1997). Ruthlessness in the family interferes with a kid's standard development of conviction besides a while later investigative practices which realize the advancement of autonomy (Leavitt and Fox, 2014). The most important factor for personality development is the home environment. Undersized family plus a small number of siblings joined with parents' involvement enhances student's presentation.

Different investigations have revealed that school age kids who are presented to family violence are influenced also to those presented to community brutality (Bell, 1995). Such adolescents much of the time give you a thought regarding a superior event of disguising (extraction, apprehension) and also externalizing (violence, criminal conduct) lead inconveniences as opposed to kids from quiet families. Quarrel between parents is an important civic health concern by virtue of its occurrence as well as risk to children's psychological well being. There is a connection between inter-parental clash plus a sense of security, protection as well as precautions in adolescence. There are differences in the pattern of family members linking inter-parental disagreement, coping manners as well as following adjustment for both genders boys and girls.

Lack of confidence in family relations lays the base for societal, exciting, cognitive along with bodily healthiness evils (Davies et al., 2008). Mooney et al., (2009) reported that parental conflict is a means mediating variable in producing downbeat outcomes in teenagers. Other researchers demonstrated that adolescent conduct issues undermine powerful child rearing and contribute to clashes among guardians and youngsters, thusly, repress child adjustment and prosperity (Ambert, 2014). There is an important relationship amongst internalizing and externalizing conduct issues and parent's behavior (Connor-Smith et al., 2000). Conflict influences child rearing quality alongside emotional and mental impacts on kids. Relationship tensions are higher associated with relationship quality than individual topics of tension. Those adolescents who are living in the conflicted home environment have a greater sense of negative world view. 
The basic reason of internalizing and externalizing behavior problems among children is conflict between parents (Clark, 2011). The outcomes of the near study demonstrate the intervening capacity of venting pessimistic assessment in the association between parental clash and youngsters' unease, give up, brutality notwithstanding a low feeling of worth moreover authority (Shelton and Harold, 2007). The advanced level of domestic violence pushes them towards mutilation, higher use of chronic drugs along with antisocial behavior. Hassan and Riaz (2012) reported that parent child relationship has great importance in the development of the personality. Kids learn through child raising practices and carries on in like manner. Children's terror plus a sense of helplessness are sensitive when offspring observer scenes in which their parents are at each other's throats. Youth behavior problems also may amplify the occurrence of inter-parental clash.

Domestic violence is not worthy and it has genuine antagonistic impacts on youngsters' conduct, advancement, scholastic achievement, and future well being. Human Rights Commission of Pakistan (1999) stated that the whole situation clearly exhibits that violence against women is an epic general prosperity and social issue in Pakistan. Females who confronted violence, report more melancholy, bring down certainty, and more ill will than in non-violent partners. Adolescents who experienced inter-parental violence has more deficits in social capability, depression, nervousness, plus personality problems than adolescents in peaceful homes. Family is the foundational source of personality development. Every family member is mutually dependent in every sphere of living with each other.

Studies show that women casualties of personal accomplice violence are at expanding hazard for poor psychological well-being (Pico-Alfonso et al., 2008; Ouellet-Morin et al., 2015). Violence produces a pointless identity. Kids in families in which the lady is battered are in danger of both physical (Campbell, 2002) and sexual exploitation. Regardless of whether youngsters are not themselves abused, living in a family in which there is a viciousness between their parents puts kids in danger. These adolescents have been found to demonstrate irregular measures of intense and introverted, as well as terrible and thwarted practices. Education works as an important mediator between rational thinking and future life outcomes in adulthood. There are several proofs that the mother's effect is superior amongst less learned parents, at the same time as the father's effect is superior among improved cultured parents. There are a lot of effects of separation as well as divorce on the behavioral evils of the adolescents. Children hates their step-mothers because they want to show solidarity with their mothers. They think that their mothers don't like if they get close to step-mothers. If mother clearly gives her consent to be like her step-mother and let her know that being nasty to step-mother is not a choice, behavior and dislike it stems from, would likely disappear. 


\section{Theoretical Framework}

Theory of social learning is presented by Albert Bandura in 1969, that focus on a mutual power linking people (behavior and cognition) as well as their situations of environment, decorated by their understandings of control. Children imitate the behavior as they have watched.

\section{Behaviorist Model}

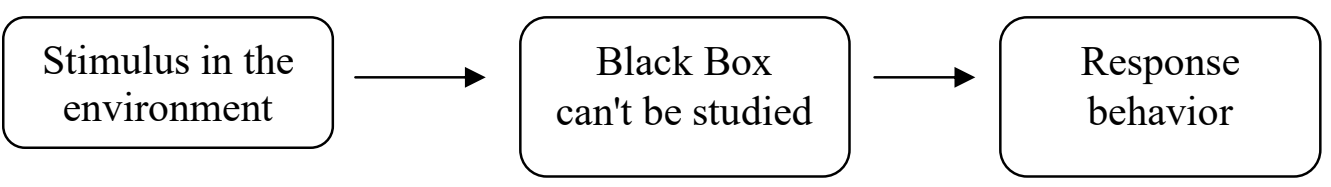

\section{Cognitive Model}

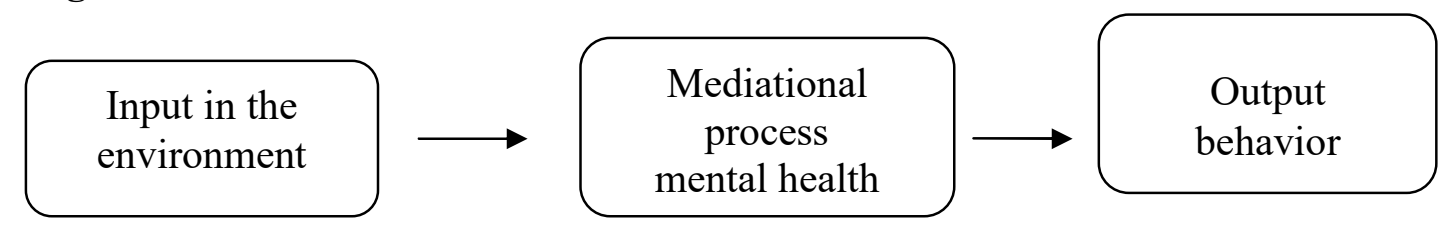

Reference: McLeod, S.A. (2011). Bandura social learning theory

\section{Reciprocal Determination}
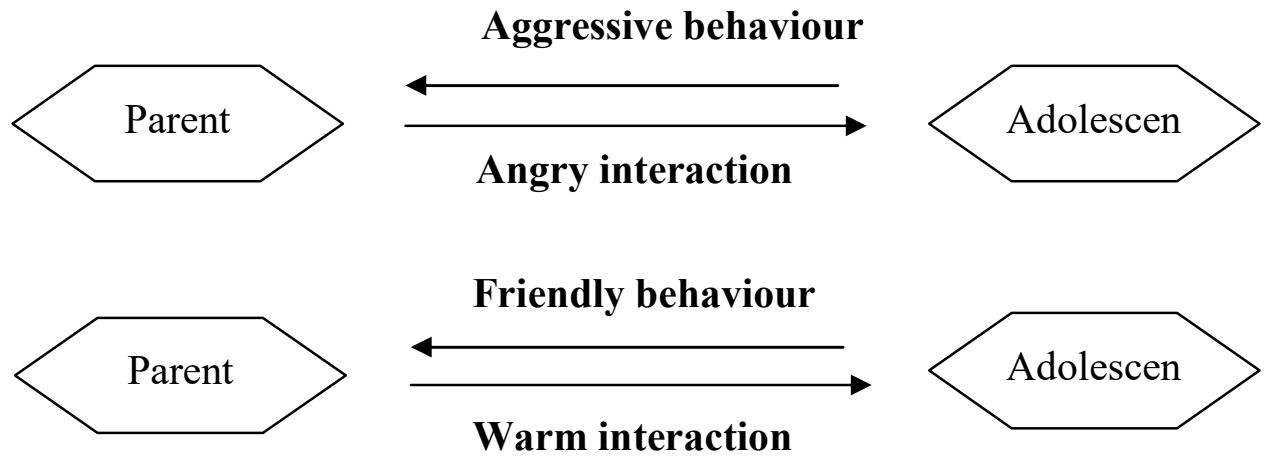

\section{Methodology}

The violence against mothers affect the personality of her adolescent was measured by means of together quantitative as well as qualitative research approaches. The integrated approach: combination of quantitative and qualitative techniques, also known as triangulation is suggested by different researchers to explore human personality problem (Zafar, 1993; Berg, 2004). The reactions are accumulated from the quantitative path 
through building up a very much outlined measuring instrument and furthermore through qualitative technique. Focus group interviews are conducted with different respondents. The District Faisalabad is chosen as a study area. The District of Faisalabad was randomly chosen through simple random sampling technique. An exploration was sorted out in Faisalabad's four urban towns. The conveyance of the region of research was comprised various union councils of urban towns of the District Faisalabad, which were randomly picked. The reason of choosing urban towns was to speak to the most extreme distinction in information.

Keeping in mind the end goal to improve the extent of the study, most extreme variety is caught in urban regions of the District from start to finish, every one of the four urban towns were chosen. A sample of 400 (adolescents and their mothers) was chosen through multistage sampling. At the main stage, four towns were conveniently chosen. From that point forward, at the second stage, four union councils from every town were picked randomly. At the third stage, 25 respondents (adolescents) aged 10 to 19 were chosen randomly from each chosen union council to explore the targets of the exploration. The respondents (mothers of adolescents) were picked through random sampling technique. Data was analyzed by using the software of statistical package of social sciences (SPSS). Uni-variate and bi-variate both techniques were utilized to find out the results of quantitative data. In uni-variate analysis, such as frequency, percentage and measures of central tendency (mean, standard deviation) were used to explain the data. In bi-variate analysis, association amongst diverse variables was examined all the way through applying chi-square in addition to gamma tests. In the qualitative examination, 8 focus group discussions of 4 to 12 ladies were gathered for gathering top to bottom data.

It was hypothesized in this study that:

$\boldsymbol{H}_{1}$ : Higher the age, higher the bad effects on personality development.

$\boldsymbol{H}_{2}$ : Female adolescent tend to have worse effects on personality development than male adolescent.

$\boldsymbol{H}_{3}$ : Higher the violence faced by mother, higher the bad effects on adolescent personality development.

$\boldsymbol{H}_{4}$ : Higher the impact of violence on mother's general health, higher the bad effects on adolescent's personality development. 


\section{Results}

Table: 1

Association between age and bad effects on personality development

\begin{tabular}{|l|c|c|c|c|}
\hline \multicolumn{5}{|c|}{ Bad effects on personality development } \\
$\%$ (Number) \\
\hline Age & Low & Medium & High & Total \\
\hline $10-14$ & $45.6(36)$ & $41.8(33)$ & $12.6(10)$ & $19.75(79)$ \\
\hline $15-19$ & $24.3(78)$ & $42.1(135)$ & $33.6(108)$ & $80.25(321)$ \\
\hline Total & $28.5(114)$ & $42.0(168)$ & $29.5(118)$ & $100.0(400)$ \\
\hline Chi-Square: 19.531 Sig. Level: $0.000 \quad$ Gamma: 0.447 Sig. Level: 0.000 \\
\hline
\end{tabular}

Chi-square value (19.531) shows a highly significant association between age of the respondents and bad effects on their personality development. The gamma value shows a strong positive relationship between the variables. As age increased the effects on personality development also increased. Mroczek \& Almeida (2004) highlighted that there is a more grounded relationship between everyday stress and negative affect for older when contrasted with more youthful grownups.

Table: 2

Association between sex and bad effects on personality development

\begin{tabular}{|l|c|c|c|c|}
\hline \multicolumn{5}{|c|}{ Bad effects on personality development } \\
$\%$ (Number) \\
\hline Sex & Low & Medium & High & Total \\
\hline Female & $25.6(79)$ & $40.9(126)$ & $33.5(103)$ & $77.0(308)$ \\
\hline Male & $38.0(35)$ & $45.7(42)$ & $16.3(15)$ & $23.0(92)$ \\
\hline Total & $28.5(114)$ & $42.0(168)$ & $29.5(118)$ & $100.0(400)$ \\
\hline Chi-Square: 11.250 Sig. Level: 0.004 Gamma: 0.317 Sig. Level: 0.001 \\
\hline
\end{tabular}

Males are more probable to understand marital conflict as a risk to themselves, while females are more possible to recognize parental conflict as a threat to the harmony of the family, feel caught in the middle of conflicts, and feel the need to intervene (Sun, 2001). Chi-square value (11.250) shows a highly significant association between sex of the respondents and bad effects on personality development. The gamma value demonstrates a positive connection between the factors. 
Table: 3

Distribution of the mothers of the adolescents according to the type of violence they faced from their husbands

\begin{tabular}{|l|c|c|c|c|c|c|c|}
\hline \multirow{2}{*}{ Violence } & \multicolumn{2}{|c|}{$\begin{array}{c}\text { To a great } \\
\text { extent }\end{array}$} & \multicolumn{2}{c|}{$\begin{array}{c}\text { To some } \\
\text { extent }\end{array}$} & \multicolumn{2}{c|}{ Not at all } & \multirow{2}{*}{ Total } \\
\cline { 2 - 8 } & Freq. & \%age & Freq. & \%age & Freq. & \%age & \\
\hline Verbal abuse & 65 & 16.25 & 179 & 44.75 & 156 & 39.0 & 400 \\
\hline Sexual violence & 7 & 1.75 & 36 & 9.0 & 357 & 89.25 & 400 \\
\hline Physical violence & 12 & 3.0 & 60 & 15.0 & 328 & 82.0 & 400 \\
\hline Emotional violence & 97 & 24.25 & 209 & 52.25 & 94 & 23.5 & 400 \\
\hline Cultural violence & 139 & 34.75 & 171 & 42.75 & 90 & 22.5 & 400 \\
\hline Financial abuse & 69 & 17.25 & 102 & 25.5 & 229 & 57.25 & 400 \\
\hline Psychological violence & 160 & 40.0 & 185 & 46.25 & 55 & 13.75 & 400 \\
\hline
\end{tabular}

Mean and Standard Deviation

\begin{tabular}{|l|c|c|c|c|c|c|c|}
\hline Mother's faced violence (discussed in above table) \\
\hline Violence No. & 1 & 2 & 3 & 4 & 5 & 6 & 7 \\
\hline Mean & 2.23 & 2.88 & 2.79 & 1.99 & 1.88 & 2.40 & 1.74 \\
\hline Std. Dev. & 0.709 & 0.380 & 0.476 & 0.692 & 0.748 & 0.766 & 0.685 \\
\hline
\end{tabular}

Violence against women occurs, though the form varies from one society and culture to another. In forty eight populations based studies from different parts of the world, ten to sixty nine percent of the women reported, having been physically assaulted by an intimate partner during their lifetime Krug et al., (2002) and approximately seventy to ninety percent of Pakistani women are subjected to domestic violence.

Table: 4

Distribution of the mothers of the respondents according to the impact of violence on their personality $n=400$

\begin{tabular}{|l|c|c|c|c|c|c|}
\hline \multirow{2}{*}{ Statements } & \multicolumn{2}{|c|}{$\begin{array}{c}\text { To a great } \\
\text { extent }\end{array}$} & \multicolumn{2}{l|}{ To some extent } & \multicolumn{2}{c|}{ Not at all } \\
\cline { 2 - 8 } & Freq. & \%age & Freq. & \%age & Freq. & \%age \\
\hline Not pay attention to children & 36 & 9.0 & 186 & 46.5 & 178 & 44.5 \\
\hline Not pay attention to domestic work & 29 & 7.25 & 195 & 48.75 & 176 & 44.0 \\
\hline Not take proper decision & 217 & 54.25 & 139 & 34.75 & 44 & 11.0 \\
\hline Not take proper diet & 257 & 64.25 & 118 & 29.5 & 25 & 6.25 \\
\hline Feel inferior after faces violence & 254 & 63.5 & 111 & 27.75 & 35 & 8.75 \\
\hline Try to kill or hurt herself & 3 & 0.75 & 41 & 10.25 & 356 & 89.0 \\
\hline
\end{tabular}


Mean and Standard Deviation

\begin{tabular}{|l|c|c|c|c|c|c|}
\hline Violence impacts on Mothers (discussed in above table) \\
\hline Statement No. & 1 & 2 & 3 & 4 & 5 & 6 \\
\hline Mean & 2.36 & 2.37 & 1.57 & 1.42 & 1.45 & 2.88 \\
\hline Std. Dev. & 0.640 & 0.615 & 0.683 & 0.608 & 0.651 & 0.345 \\
\hline
\end{tabular}

Sometimes, violence that happened long ago still can affect. Sexual violence can have psychological, emotional, and physical effects on a survivor. In the theoretical perspective, the theory of social learning shows that adolescents learn from their parents and environment. On a worldwide scale, the human toll of viciousness, in excess of 1.6 million lives lost each year and perpetual more hurt in manners that are not for the most part self-evident, but instead revealed the numerous appearances of social, gathering and self-coordinated viciousness, and what's more, the settings in which fierceness occurs. There is an average association between forceful conduct at home and youth maul. Youngsters may encounter uneasiness, wretchedness, disgrace or different issues when clashed parental connections result in useless child rearing practices.

\section{Qualitative Analysis}

The researcher serves several functions in the focus group: moderator, listener, observer and eventually analyst (Krueger and Casey, 2014).

\section{Marital Relationship Affects Adolescent's Personality Development}

A number of women expressed that there are effects of parental marital quality on child well-being (mental and physical health). Marital conflict leads to adolescent adjustment problems, whether changes in marital conflict predict changes in adolescent problems. A happy parental relationship is important for adolescent positive personality development. A mother reported that "in families where marital conflict is at peak, children feel themselves unlucky and avoid to participate in any social activity." Members also reported that "witnessing high levels of destructive conflict between parents have been associated with greater child distress and negative thoughts in light of disputation." Regardless of the possibility that it's not the parents' expectation to cause hurt, continuous clash can undermine a youngster's feeling of well being.

\section{Contribution of Violence in Adolescent's Personality Development}

Most members complained about their husbands and in laws as they used to inflict verbal abuse. Mothers expressing their views with a feeling of embarrassment. As a matter of fact, it involved disgrace to state that they are feeble, having nothing to do with any family matter and for the most part beaten by their spouses and in laws. It is 
vital to take note of that violent conduct with mothers in a roundabout way influences adolescent identity advancement. These social values and segregating demeanors towards ladies extremely influenced the identity of the mother and immature. Childhood and immaturity is the time when a person builds up his or her recognitions about parental connections and identity improvement. It is the time when a legitimate direction will help him or her to be a suitable common society part and in addition a superior individual.

\section{Conclusions}

To a noteworthy degree the identity of a pre-adult relies upon the family condition. In developing countries like Pakistan the parental conflict considers not a big issue. It is the story of every home. The participants were belonging to different age groups and different backgrounds. They had different number of children too. At the point when a few members were examined, one of the members said "kids usually keep quiet, it implies they are not developing admirably". While one respondent mother of 5 youngsters had the supposition "For the most part my little girl cry. This is altogether because of parental clash". Just three ladies plainly realized that what is parental clash and its connection with the juvenile identity advancement. They had genuine data because of their kids' mental issues. Where, the specialist had revealed to them that their youngsters have a headache and mental issue because of strains.

Most of the respondents in all FGDs viewed that their children have feelings of inferiority, like to be alone, disobey their parents and irritated attitude. This is altogether described with personality issues. A couple of ladies think about adolescent's identity advancement, yet they can't do anything to improve their condition on account of neediness, ignorance, and social restrictions nearby the oppressive perspective of the spouses and in-laws. Every couple fights, but when bruises become part of the picture, getting out before it's too late may save a person's life. Research shows that disclosure to mercilessness happens when youngsters see, hear, are direct drawn in with (i.e., attempt to intervene), or experience the outcomes of physical or rapes that occur between their parental figures.

The examination has likewise attempted to discover the effect of violence on mother's standard life. It was seen that personality development is essentially connected with the violent behavior in evident ways. The Male centric setup, the conduct of in-laws, destitution and birth of a baby girl were nearly connected with higher physical and psychological mistreatment. Several problems as mothers didn't take proper decision, proper diet, felt inferior and didn't pay proper attention to children closely linked to violence. Inter-parental conflicts absolutely linked to both internalizing and externalizing personality problems in adolescents. It is concluded that the extent of 
parental conflict is at higher risk of personality disorder. Additionally, mothers who encounter spouse violence, their children are at more serious danger of antagonistic personality development. They are very focused, physically unfortunate and sad. The mother's fierce state of mind is additionally confusing adolescent's personality development.

\section{Recommendations}

To remove violence against women some genuine endeavors are required, which ought to be efficient, very much organized and practical.

- The state should take responsibility to take every accessible measure to make sure that adolescent rights (e.g., wellbeing facilities) are regarded, secured, and fulfilled.

- Parents should realize that adolescents are hurt less by divorce than by experiencing the severe conflict, whether their families are intact, dissolving, or wrecked.

- Never reprimand adolescent for whining, crying or staying aloof. Try to find out the reason behind the unnatural behavior.

- The husband should behave politely with her wife to keep peaceful home environment.

- Both spouses have to understand the rights of each other. In this way violence will demolish and children will raise positively.

\section{References}

Ambert, A. M. (2014). Changing Families: Relationships in Context. Pearson Education Canada.

Bandura, A. (1969). Social-learning Theory of Identificatory Processes. Handbook of Socialization Theory and Research, 213, 262.

Bell, C. (1995). Exposure to Violence Distresses Children and May Lead to their Becoming Violent. Psychiatric News, 15, 6-8.

Berg, B. L. (2004). Methods for the Social Sciences. Pearson Education Inc, United States of America.

Bronstein, P. (1994). Patterns of Parent-Child Interaction in Mexican Families: A CrossCultural Perspective. International Journal of Behavioral Development, vol.17:3, pp.423-446. 
Campbell, J. C. (2002). Health Consequences of Intimate Partner Violence. The Lancet, $359(9314)$.

Clark, A. M. (2011). The Impact of Marital Conflict on Parenting and Adolescent Prosocial Behavior. Master of Science Thesis, Brigham Young University.

Connor-Smith, J. K., Compas, B. E., Wadsworth, M. E., Thomsen, A. H. \& Saltzman, H. (2000). Responses to Stress in Adolescence: Measurement of Coping and Involuntary Stress Responses. Journal of Consulting and Clinical Psychology, vol.68:6, pp.976-992.

Davies, P. T., Woitach, M. J., Winter, M. A. \& Cummings, E. M. (2008). Children's Insecure Representations of the Interparental Relationship and their School Adjustment: The Mediating Role of Attention Difficulties. Child Development, vol.79:5, pp.1570-1582.

Eisenberg, N., Zhou, Q. \& Koller, S. (2001). Brazilian Adolescents' Pro-Social Moral Judgment and Behavior: Relations to Sympathy, Perspective Taking, Gender-Role Orientation and Demographic Characteristics. Child Development, vol.72:2, pp.518-534.

Encyclopedia of Psychology. (2017). Retrieved from: http://psychology.oxfordre.com/

Eugster, K. (2007). Chronic Parental Conflict: How it can be harmful for children. Retrieved from: http://www.kathyeugster.com/articles/article002.htm

Ezeah, P. (2013). Socio-Economic and Cultural Processes Associated with Domestic Violence in Rural Nigeria: A Study of Uzo Uwani Local Government Area of Enugu State. Bangladesh e-Journal of Sociology, vol.10:1, pp.92-100.

Fantuzzo, J., Boruch, R., Beriama, A., Atkins, M. \& Marcus, S. (1997). Domestic Violence and Children: Prevalence and Risk in Five Major US Cities. Journal of the American Academy of Child \& Adolescent Psychiatry, vol.36:1, pp.116-122.

Garcia-Moreno, C., Jansen, H. A., Ellsberg, M., Heise, L. \& Watts, C. H. (2006). Prevalence of Intimate Partner Violence: Findings from the WHO Multi-Country Study on Women's Health and Domestic Violence. The lancet, vol.368:9543, pp.1260-1269. 
Hassan, F., Sadowski, L. S., Bangdiwala, S. I., Vizcarra, B., Ramiro, L., De Paula, C. S. \& Mitra, M. K. (2004). Physical Intimate Partner Violence in Chile, Egypt, India and the Philippines. Injury Control and Safety Promotion, vol.11:2, pp.111-116.

Hassan, S. B. \& Riaz, M. N. (2012). Perception of Parental Acceptance and Rejection in Emotionally Empathic and Non-Empathic Adolescents. Pakistan Journal of Social and Clinical Psychology, vol.10:2, pp.60-69.

Heise, L., Ellsberg, M. \& Gottmoeller, M. (2002). A Global Overview of Gender-Based Violence. International Journal of Gynecology \& Obstetrics, vol.78:S1.

Human Rights Commission of Pakistan. (1999). State of Human Rights in 1999. Lahore.

Khosla, A., Dua, D., Devi, L. \& Sud, S. (2005). Domestic Violence in Pregnancy in North Indian Women. Indian Journal of Medical Sciences, vol.59:5, p.195.

Krueger, R. A. \& Casey, M. A. (2014). Focus Groups: A Practical Guide for Applied Research. Sage Publications.

Krug, E. G., Mercy, J. A., Dahlberg, L. \& Zwi, A. B. (2002). The World Report on Violence and Health. The Lancet, 360(9339), 1083-1088.

Leavitt, L. A. \& Fox, N. A. (2014). The Psychological Effects of War and Violence on Children. Psychology Press.

Martins, C. \& Gaffan, E. A. (2000). Effects of Early Maternal Depression on Patterns of Infant-Mother Attachment: A Meta-Analytic Investigation. The Journal of Child Psychology and Psychiatry and Allied Disciplines, vol.41:6, pp.737-746.

McLeod, S.A. (2011). Bandura Social Learning Theory. Retrieved from: https://www.simplypsychology.org/simplypsychology.org-bandura.pdf

Mooney, A., Oliver, C. \& Smith, M. (2009). Impact of Family Breakdown on Children's Well-Being: Evidence Review. Thomas Coram Research Unit, Institute of Education, University of London.

Mroczek, D. K. \& Almeida, D. M. (2004). The Effect of Daily Stress, Personality, and Age on Daily Negative Affect. Journal of Personality, vol.72:2, pp.355-378. 
Ouellet-Morin, I., Fisher, H. L., York-Smith, M., Fincham-Campbell, S., Moffitt, T. E. \& Arseneault, L. (2015). Intimate Partner Violence and New-Onset Depression: A Longitudinal Study of Women's Childhood and Adult Histories of Abuse. Depression and Anxiety, vol.32:5, pp.316-324.

Osofsky, J. D. (1999). The Impact of Violence on Children. The Future of Children, pp.33-49.

Pakistan Bureau of statistics. (2017). Retrieved from:http://www.pbs.gov.pk/

Pervez, S. \& Khalid, I. (2018). Gender Discrimination - Prevailing State in Pakistan. Pakistan Journal of Gender Studies, Vol. 16, pp. 153-170.

Pico-Alfonso, M. A., Echeburúa, E. \& Martinez, M. (2008). Personality Disorder Symptoms in Women as a Result of Chronic Intimate Male Partner Violence. Journal of Family Violence, vol.23:7, pp.577-588.

Renzetti, C. M. (1994). On Dancing with a Bear: Reflections on Some of the Current Debates among Domestic Violence Theorists. Violence and Victims, vol.9:2, p.195.

Schermerhorn, A. C., Cummings, E. M., DeCarlo, C. A. \& Davies, P. T. (2007). Children's Influence in the Marital Relationship. Journal of Family Psychology, vol.21:2, p.259.

Shelton, K. H. \& Harold, G. T. (2007). Marital Conflict and Children's Adjustment: The Mediating and Moderating Role of Children's Coping Strategies. Social Development, vol.16:3, pp.497-512.

Sun, Y. (2001). Family Environment and Adolescents' Well-Being Before and After Parents' Marital Disruption: A Longitudinal Analysis. Journal of Marriage and Family, vol.63:3, pp.697-713.

Thompson, R. A., Lewis, M. D. \& Calkins, S. D. (2008). Reassessing Emotion Regulation. Child Development Perspectives, vol.2:3, pp.124-131.

UNICEF. (2000). Breaking the Earthenware Jar: Lessons from South Asia to End Violence against Women and Girls. Figures from the Bangladesh Bureau of Statistics. In: Hayward, Ruth Finney. New York: UNICEF; 2000. 
UNICEF. (2006). Behind Closed Doors: The Impact of Domestic Violence on Children. In Behind Closed Doors: The Impact of Domestic Violence on Children. UNICEF.

Zafar, M. I. (1993). The Correlates of Contraceptive and Fertility Behaviour within the Framework of Sociological Ideology: A Case Study of Two Urban Centres of Pakistan (Doctoral dissertation, University of Exeter).

Madieha Akram is Ph.D Scholar in the Department of Sociology, Government College University, Faisalabad.

Dr. Zahira Batool is Chairperson in the Department of Sociology, Government College University, Faisalabad. 